\title{
Studi Pengaruh Jumlah Rekahan Terhadap Kuat Tekan Uniaksial dan Kecepatan Gelombang Ultrasonik
}

\author{
Aditya Budi Nugraha*, Ridho Kresna Wattimena, Tedy Setiawan
}

Program Studi Rekayasa Pertambangan, Institut Teknologi Bandung, Bandung, Indonesia

* Corresponding author: kang.abnugraha@gmail.com

Received: Jan 8, 2021; Accepted: Jun 16, 2021.

DOI: $10.31764 /$ jpl.v2i1.3837

\begin{abstract}
Abstrak. Keberadaan rekahan merupakan keadaan yang umum terjadi dalam massa batuan. Pendeteksian rekahan dalam massa batuan merupakan hal yang sangat penting dalam pekerjaan pertambangan. Rekahan pada massa batuan secara umum mengurangi kekuatan dalam massa batuan tersebut. Salah satu metode yang umum digunakan dalam mendeteksi keberadaan rekahan adalah dengan non destructive test (NDT), yang mana menggunakan gelombang ultrasonik (kecepatan gelombang $\mathrm{P} / \mathrm{Vp}$ ) sebagai media pengukur. Vp merupakan parameter yang dipengaruhi oleh keberadaan rekahan tersebut. Selain itu, dipelajari mengenai pengaruh rekahan terhadap nilai kuat tekan. Sampel yang digunakan merupakan beton dengan komposisi campuran semen - pasir 1:1 dan 1:3. Dua komposisi campuran tersebut dibuat sebagai representasi dari kekuatan batuan yang lemah dan kuat. Rekahan yang dibuat berupa rekahan artifisial pada sampel berukuran $5,4 \mathrm{~cm} \times 12 \mathrm{~cm}$ dengan variasi jumlah rekahan untuk setiap komposisi.
\end{abstract}

Kata Kunci: gelombang ultrasonik, kecepatan gelombang, rekahan, kuat tekan.

Abstract. The existence of fractures is a common condition in rock masses. The detection of fractures in rock mass is very important in mining project. Fractures that existence in rock mass generally reduce strength of the rock masses. The methods commonly used in examining fractures is the non-destructive test (NDT), it's use ultrasonic waves (P wave velocity) as measurement media. In this study discussed also the effect of fracture to the compressive strength. The sample used is concrete with a cement-sand mixture composition is $1: 1$ and 1: 3. This two compositions represent the strength of rock, one mixture represent weak rocks and other mixture represent strong rocks. The fractures made as artificial fractures in the sample which sample dimension is 5.4 $\mathrm{cm} \times 12 \mathrm{~cm}$ with a variation in the number of fractures for each composition.

Keywords: ultrasonic wave, wave velocity, fracture, compressive strength.

\section{Pendahuluan}

Gelombang ultrasonik didefinisikan sebagai gelombang dengan band frekuensi di atas $20 \mathrm{kHz}$, dan menerus sampai dengan orde $\mathrm{MHz}$ dan berakhir pada frekuensi sekitar $1 \mathrm{GHz}$. Aplikasi dari gelombang ultrasonik telah banyak digunakan pada berbagai disiplin ilmu seperti kimia, fisika, teknik, biologi, oseanografi, kesehatan, seismologi, dll. Terdapat dua alasan utama sehingga gelombang ultrasonik digunakan dalam bidang-bidang tersebut (Cheeke, 2002), yaitu: (1) Gelombang ultrasonik merambat dengan lambat sekitar 100.000 kali lebih lambat dari gelombang elektromagnetik. Hal ini memberikan jalan untuk menampilkan informasi pada waktunya, membuat variabel tunda, dll. (2) Gelombang ultrasonik dapat menembus material opaque dengan mudah, yang mana tipe radiasi lain tidak dapat menembusnya. Selain itu, sumber gelombang ultrasonik tergolong tidak mahal, sensitive, dan handal. Hal ini memberikan cara yang baik untuk menyelidiki dan menggambarkan interior dari material tersebut.

Pada studi ini jenis gelombang ultrasonik yang digunakan adalah gelombang $\mathrm{P}$ dengan parameter yang digunakan dalam pengukuran adalah kecepatan gelombang $\mathrm{P}(\mathrm{Vp})$. Pengaruh rekahan terhadap Vp terlihat dari laju diminusinya, pada batuan sampel calcarenite of sale dan marble of oued Akrech (MA) diminusi yang terjadi yaitu antara $8 \%-42 \%$ dan bernilai $100 \%$ pada rekahan ke-8 (El Azhari et al., 2013). Jarak spasi antar rekahan juga mempengaruhi kecepatan gelombang $\mathrm{P}(\mathrm{Vp})$, dengan menggunakan parameter Velocity Reduction Ratio (VRR) untuk spasi antar rekahan sebesar $2 \mathrm{~cm}$ dan $5 \mathrm{~cm}$ diperoleh hasil untuk jumlah rekahan kurang dari 3, nilai VRR lebih tinggi untuk spasi rekahan $5 \mathrm{~cm}$, sedangkan untuk jumlah rekahan lebih dari 3, hasilnya adalah sebaliknya. Selain itu, laju VRR pada spasi yang lebih pendek menjadi lebih steep (Fathollahy et al., 2017). Nilai Vp 
cenderung berkurang ketika melalui rekahan, pada batuan marble dan travertine nilai $\mathrm{Vp}$ terus turun seiring bertambahnya rekahan (Jaroenklang, 2018).

\section{Metode Penelitian}

Sampel dibuat adalah sampel dengan campuran pasir dan beton dengan rasio semen:pasir 1:1 dan 1:3. Dimensi dari sampel yaitu (D x L) $\pm 5,4 \mathrm{~cm} \times \pm 12 \mathrm{~cm}$, sesuai dengan standar ISRM yaitu L/D bernilai $2-2,5$. Digunakannya standar ISRM karena sampel akan diuji dengan metode uji UCS. Maksud dari dibuatnya dua rasio campuran ini adalah untuk merepresentasikan perbedaan kekuatan dari sampel, satu rasio merepresentasikan sampel yang lebih kuat dan rasio yang lain merepresentasikan sampel yang lebih lemah. Peralatan yang digunakan dalam pengujian adalah: (1) Mesin UCS Merk Hung Ta, untuk pengujian UCS dan (2) Ultracon 170 untuk pengukuran Vp.

Pembentukan rekahan pada sampel dibuat dengan cara dipotong menggunakan mesin potong di Laboratorium Mekanika Batuan ITB. Pola pemotongan rekahan terlihat pada gambar 1. Terdapat sampel yang utuh atau tidak dipotong dan sampel lain yang dibuat rekahan artifisial berjumlah satu, dua dan tiga rekahan.
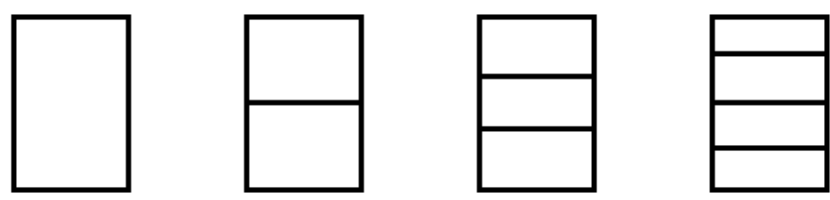

Gambar 1. Bentuk sampel yang digunakan dalam pengujian

Perbedaan jumlah rekahan tersebut dimaksudkan untuk mengetahui pengaruh jumlah rekahan terhadap nilai kuat tekan dan nilai Vp. Sebelum dipotong, Vp dari sampel terlebih dahulu diukur, hasil dari pengukuran tersebut terdapat pada tabel 1. Pada gambar 2 dan 3 terlihat bahwa nilai Vp pada sampel relatif sama, untuk sampel dengan rasio 1:1 nilai Vp berada pada jarak yang dekat (sekitar 3000an) dengan nilai rata-rata $2994 \mathrm{~m} / \mathrm{s}$. sedangkan pada sampel dengan rasio 1:3 nilai Vp juga berada pada jarak yang relatif dekat (sekitar 2000an) dengan nilai rata-rata 2060.

Nilai Vp yang relatif dekat antara satu sampel dan sampel yang lain pada rasio komposisi yang sama dapat diasumsikan bahwa kekuatan sampel untuk komposisi yang sama adalah setara.

Tabel 1. Vp sampel pada kondisi utuh

\begin{tabular}{|c|c|c|c|c|c|}
\hline \multirow{2}{*}{$\begin{array}{c}\text { Kode } \\
\text { Sampel }\end{array}$} & \multicolumn{3}{|c|}{ Vp untuk pengambilan ke } & \multirow{2}{*}{$\begin{array}{l}\text { Vp rata- } \\
\text { rata }(\mathrm{m} / \mathrm{s})\end{array}$} & \multirow{2}{*}{$\begin{array}{l}\text { Vp rata-rata tiap } \\
\text { komposisi }(\mathbf{m} / \mathbf{s})\end{array}$} \\
\hline & $1(\mathrm{~m} / \mathbf{s})$ & $2(\mathrm{~m} / \mathrm{s})$ & $3(\mathrm{~m} / \mathrm{s})$ & & \\
\hline $1: 1-1$ & 3013 & 3012 & 3010 & 3012 & \multirow{4}{*}{2994} \\
\hline $1: 1-3$ & 3018 & 3016 & 3016 & 3017 & \\
\hline $1: 1-5$ & 2912 & 2912 & 2913 & 2912 & \\
\hline $1: 1-7$ & 3031 & 3034 & 3035 & 3033 & \\
\hline $1: 3-2$ & 2042 & 2045 & 2049 & 2045 & \multirow{4}{*}{2060} \\
\hline $1: 3-3$ & 2046 & 2045 & 2044 & 2045 & \\
\hline $1: 3-6$ & 2029 & 2028 & 2029 & 2029 & \\
\hline $1: 3-8$ & 2119 & 2120 & 2118 & 2119 & \\
\hline
\end{tabular}




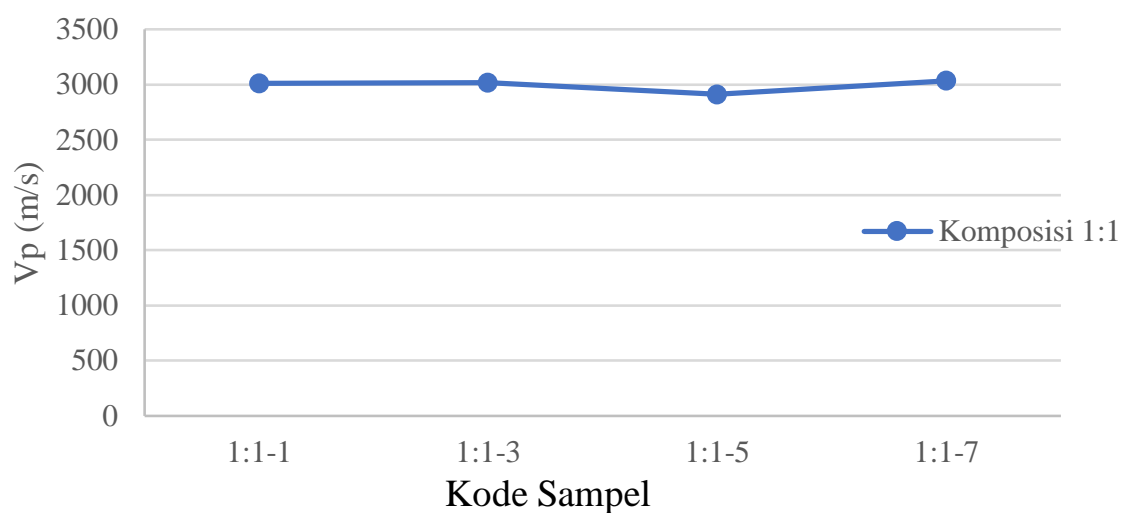

Gambar 2. Nilai Vp utuh pada rasio komposisi 1:1

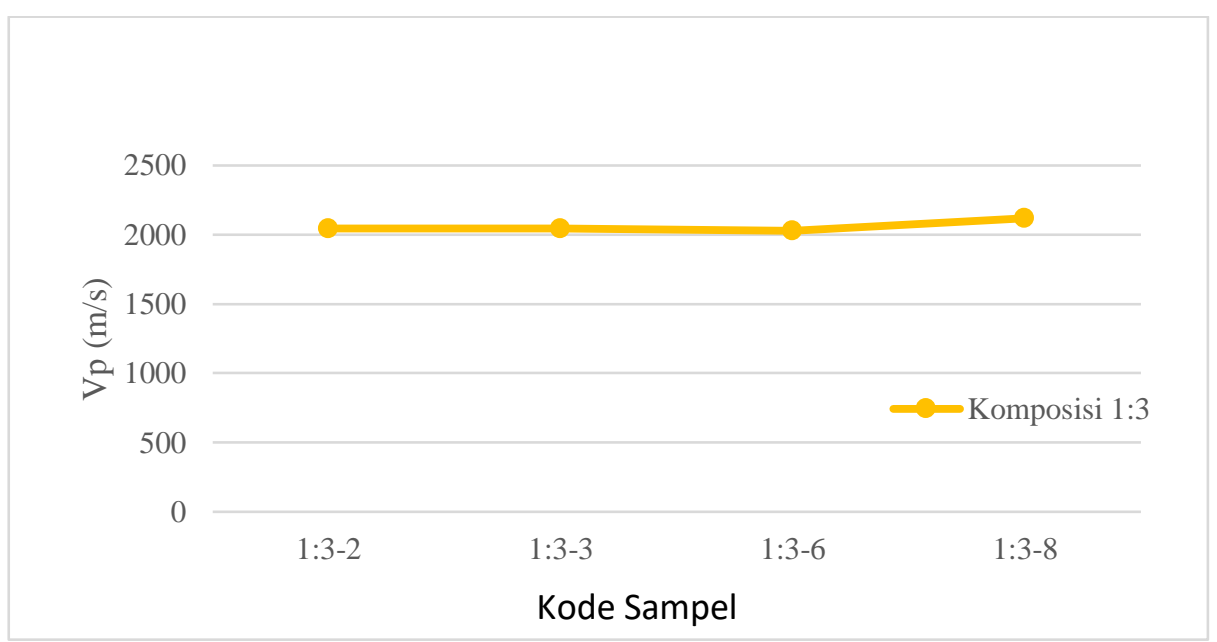

Gambar 3. Nilai Vp utuh pada rasio komposisi 1:3

Hasil pengukuran Vp pada konsisi utuh dan rekah serta nilai kuat tekan uniaksial dari keseluruhan sampel dengan komposisi 1:1 dan 1:3 dapat dilihat pada tabel 2.

Tabel 2. Nilai Vp dan UCS pada sampel dan diminusinya

\begin{tabular}{cccccc}
\hline $\begin{array}{c}\text { Kode } \\
\text { Sampel }\end{array}$ & $\begin{array}{c}\text { Jml } \\
\text { Rekahan }\end{array}$ & $\begin{array}{c}\mathbf{V p} \\
(\mathbf{u t u h}) \\
\mathbf{m} / \mathbf{s}\end{array}$ & $\begin{array}{c}\mathbf{V p}(\text { rekahan) } \\
\mathbf{m} / \mathbf{s}\end{array}$ & $\begin{array}{c}\text { Kuat Tekan - } \\
\text { UCS (MPa) }\end{array}$ & $\begin{array}{c}\text { Diminusi } \\
(\%)\end{array}$ \\
$1: 1-1$ & 0 & 3012 & 3012 & 44,1 & 0 \\
$1: 1-3$ & 1 & 3017 & 2734 & 30,1 & 9,38 \\
$1: 1-5$ & 2 & 2912 & 1824 & 13,1 & 37,36 \\
$1: 1-7$ & 3 & 3033 & 969 & 9,2 & 68,05 \\
$1: 3-2$ & 0 & 2045 & 2045 & 13,5 & 0 \\
$1: 3-3$ & 1 & 2045 & 1948 & 10,8 & 4,75 \\
$1: 3-6$ & 2 & 2029 & 962 & 8,4 & 52,59 \\
$1: 3-8$ & 3 & 2119 & 532 & 5,5 & 74,89 \\
\hline
\end{tabular}


Dalam penelitian ini digunakan parameter diminusi, diminusi menggambarkan kehilangan $\mathrm{Vp}$ akibat adanya rekahan. Perhitungan diminusi pada sampel dapat dilihat pada tabel 2. Persamaan diminusi adalah sebagai berikut:

$$
D=\frac{V p_{u t u h}-V p_{\text {rekah }}}{V p_{u t u h}} \times 100 \%
$$

\section{Hasil dan Pembahasan}

Nilai Vp yang dihasilkan dari hasil pengukuran memperlihatkan adanya penurunan untuk setiap tambahan rekahan, hal yang sama juga terjadi pada nilai kuat tekan uniaksial. Hubungan antara Vp dengan jumlah rekahan terlihat pada gambar 4 . Terlihat pada grafik di gambar $4 \mathrm{Vp}$ turun seiring dengan jumlah rekahan. Jika dibuat regresi dari data tersebut diperoleh hubungan berupa persamaan untuk Vp dan jumlah rekahan. Persamaan regresi untuk rasio campuran 1:1 adalah:

$$
V p=-703,77(J R)+3190,2
$$

dengan JR adalah jumlah rekahan, sedangkan persamaan regresi untuk rasio campuran 1:3 adalah:

$$
V p=-552,6(J R)+2200,6
$$

Pada gambar 4, grafik yang berwarna biru merepresentasikan sampel dengan rasio campuran 1:1 sedangkan grafik yang berwarna oranye merepresentasikan sampel dengan rasio campuran 1:3.

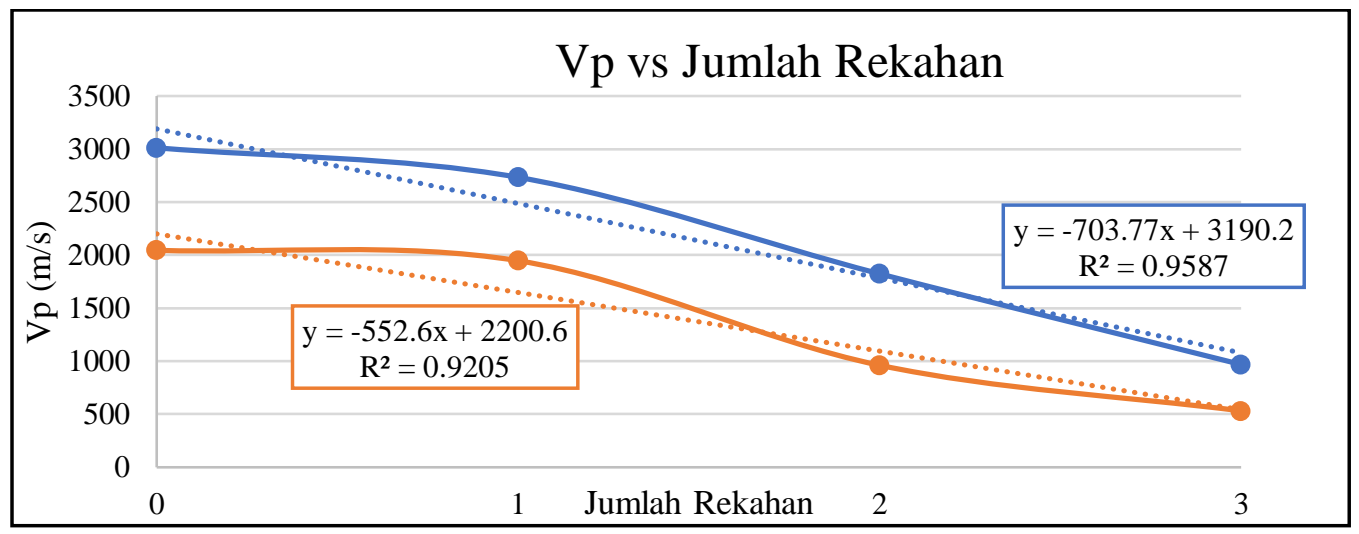

Gambar 4. Grafik hubungan Vp terhadap jumlah rekahan untuk kedua komposisi

Seperti terlihat pada gambar 4 nilai $\mathrm{Vp}$ terus turun seiring dengan pertambahan rekahan, parameter yang menggambarkan penurunan kecepatan seiring dengan penambahan jumlah rekahan adalah diminusi. Hubungan antara nilai diminusi dengan jumlah rekahan terlihat pada gambar 5.

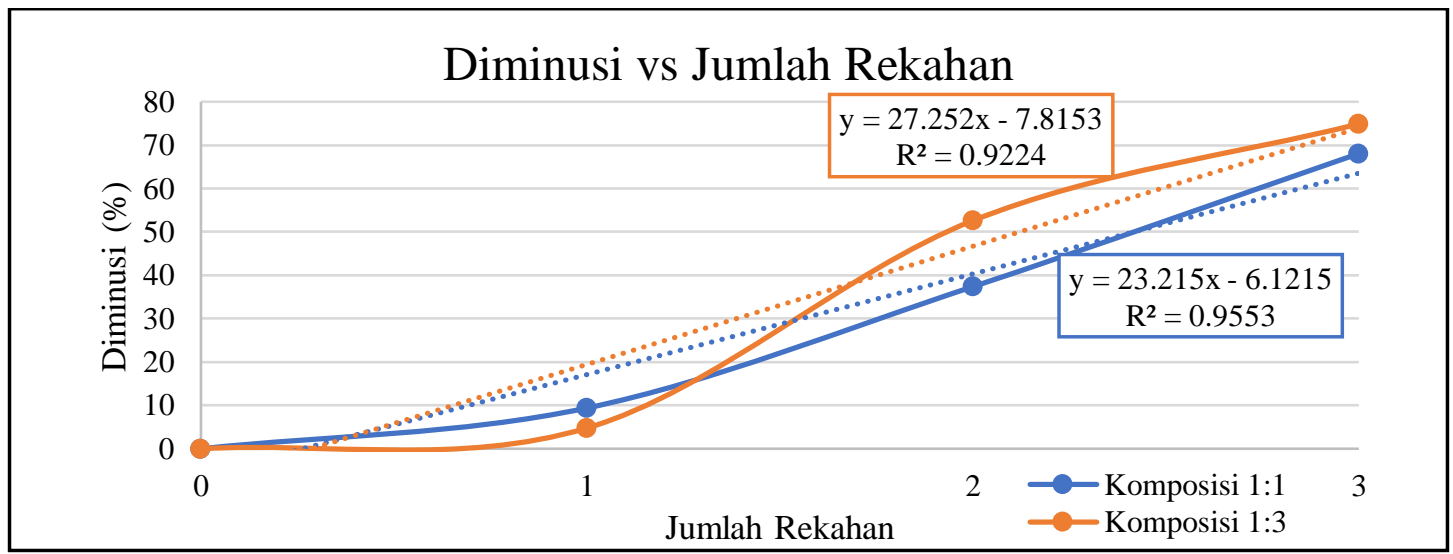

Gambar 5. Hubungan diminusi dengan jumlah rekahan

Jika persamaan yang dihasilkan dari hubungan diminusi dengan jumlah rekahan digunakan untuk mengetahui seberapa banyak rekahan yang akan mengakibatkan nilai diminusinya $100 \%$, maka diketahui bahwa nilai diminusi untuk komposisi dengan rasio campuran 1:1 membutuhkan 5 rekahan 
sampai nilai diminusinya $100 \%$ atau lebih dari $100 \%$. Nilai diminusi $100 \%$ menggambarkan nilai Vp sudah tidak terbaca pada alat. Sedangkan untuk komposisi dengan rasio campuran 1:3 memerlukan 4 rekahan sampai nilai diminusinya melebihi 100\% seperti terlihat pada tabel 3 .

Tabel 3. Perhitungan diminusi untuk penambahan jumlah rekahan

\begin{tabular}{|l|r|r|}
\hline $\begin{array}{c}\text { Kode } \\
\text { Sampel }\end{array}$ & $\begin{array}{r}\text { Jml } \\
\text { Rekahan }\end{array}$ & $\begin{array}{c}\text { Diminusi } \\
(\%)\end{array}$ \\
\hline $1: 1-1$ & 0 & 0,00 \\
\hline $1: 1-3$ & 1 & 9,38 \\
\hline $1: 1-5$ & 2 & 37,37 \\
\hline $1: 1-7$ & 3 & 68,05 \\
\hline $1: 1-X$ & 4 & 86,7385 \\
\hline $1: 1-Y$ & 5 & 109,9535 \\
\hline $1: 3-2$ & 0 & 0,00 \\
\hline $1: 3-3$ & 1 & 4,76 \\
\hline $1: 3-6$ & 2 & 52,60 \\
\hline $1: 3-8$ & 3 & 74,89 \\
\hline $1: 3-X$ & 4 & 101,19 \\
\hline
\end{tabular}

Pada kuat tekan hal yang sama juga terjadi, dimana nilai kuat tekan berkurang seiring dengan penambahan jumlah rekahan seperti terlihat pada gambar 6. Dari grafik dalam gambar 6 dapat disimpulkan bahwa nilai kuat tekan akan turun seiring dengan penambahan jumlah rekahan. Hubungan antara kuat tekan dan jumlah rekahan dapat diwakili melalui persamaan yang diperoleh dari regresi linear pada grafik di gambar 6.

Persamaan hubungan kuat tekan dengan jumlah rekahan untuk komposisi 1:1, adalah:

$$
U C S=-12,166(J R)+42,364
$$

Sedangkan persamaan hubungan kuat tekan dengan jumlah rekahan untuk komposisi 1:3, adalah:

$$
U C S=-2,64(J R)+13,51
$$

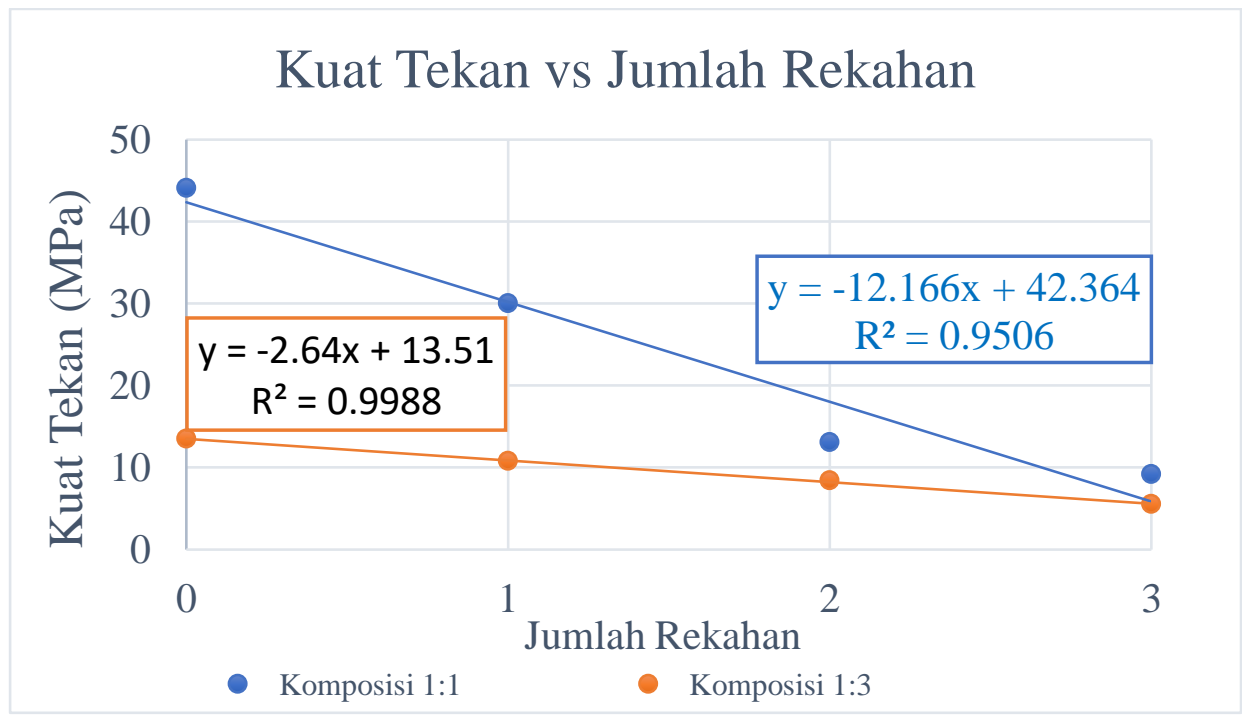

Gambar 6. Grafik hubungan kuat tekan (UCS) dengan jumlah rekahan

\section{Kesimpulan}

Kesimpulan yang diperoleh pada studi ini, yaitu:

1. Nilai Vp dapat merepresentasikan kekuatan dari sampel, terlihat bahwa nilai Vp pada sampel dengan campuran 1:1 lebih tinggi dibandingkan sampel dengan campuran 1:3.

2. Jumlah rekahan akan menurunkan nilai kuat tekan uniaksial dan kecepatan gelombang P.

3. Berdasarkan nilai diminusi, sampel dengan kuat tekan yang lebih baik/lebih kuat memerlukan jumlah rekahan yang lebih banyak untuk membuat nilai diminusinya $100 \%$ dibandingkan dengan sampel yang kekuatannya lebih lemah. 


\section{Ucapan Terima Kasih}

Ucapan terima kasih saya ucapkan kepada Program Studi Magister Rekayasa Pertambangan dan Teknik Geofisika, Fakultas Teknik Pertambangan dan Perminyakan, Institut Teknologi Bandung yang telah mendukung penelitian ini.

\section{Referensi}

Cheeke, J. D. N., (2002) Fundamentals and Applications of Ultrasonic Waves: CRC Press

El Azhari, H. and El Hassani, I. E A., (2013) 'Effect of the Number and Orientation of Fractures on the P-Wave velocity Diminution: Application on the Building Stode of the Rabat Area (Morocco)', Journal Geomaterial, doi:10.4236/gm.2013.33010

Fathollahy, M. and Uromeiehy, A. and Riahi, M. A., (2017) 'Evaluation of P-Wave Velocity in different Joint Spacing', Bolletino di Geofisica Teorica ed Applicata, Vol 58, n.3, pp 157-168.

Leucci, G. and De Giorgi, L., (2006) 'Experimental studies on the effects of fracture on the P and S Wave Velocity Propagation in Sedimentary Rock ("Calcarenite del Salento")', Journal Engineering Geology Elsevier, doi:10.1016/j.enggeo.2005.12.004.

Mejia, A. I. and Niemann, J. D. (2008) 'Identification and Characterization of Dendritic, Parallel, Pinnate, Rectangular, and Trellis Networks based on Deviations from Planform SelfSimilarity', Journal of Geophysical Research, 113(F02015), pp. 1-21. doi: 10.1029/2007JF000781.

Rai, M. A., Kramadibrata, S., Wattimena. (2012) Mekanika Batuan: ITB Press 